\title{
Effect of Anogeissus leiocarpus Guill and Perr Leaf on Hyperglycaemia and Associated Dyslipidaemia in Alloxan-induced Diabetic Rats
}

\author{
Uwakwe S. Onoja ${ }^{1}$, Cynthia C. Ugwu ${ }^{1}$, Philip F. Uzor ${ }^{2}$, Innocent E. Nweze ${ }^{3}$, \\ Edwin 0. Omeje $\mathrm{e}^{2}$, Petra O. Nnamani ${ }^{4}$, Ekere Nwachukwu ${ }^{5}$, Ivoke Njoku ${ }^{6}$ \\ and Eyo J. Effiong ${ }^{6}$ \\ ${ }^{1}$ Department of Nutrition and Dietetics, University of Nigeria, Nsukka 410001, Enugu State, Nigeria \\ ${ }^{2}$ Department of Pharmaceutical and Medicinal Chemistry, University of Nigeria, Nsukka 410001 \\ Enugu State, Nigeria \\ ${ }^{3}$ Department of Microbiology, University of Nigeria, Nsukka 410001, Enugu State, Nigeria \\ ${ }^{4}$ Department of Pharmaceutics, University of Nigeria, Nsukka 410001, Enugu State, Nigeria \\ ${ }^{5}$ Department of Pure and Applied Chemistry, University of Nigeria, Nsukka 410001, Enugu State, Nigeria \\ ${ }^{6}$ Department of Zoology and Environmental Biology, University of Nigeria, Nsukka 410001 \\ Enugu State, Nigeria
}

(Received: 9 January, 2018; Accepted: 19 March, 2018; Published (web): 10 June, 2018)

\begin{abstract}
People living with diabetes mellitus across the world are expected to rise to 592 million by 2035 and the pandemic disease is worst in the developing countries like Nigeria, where the cost of treating/managing diabetes mellitus is relatively out of the reach of many diabetic patients. The study investigated the effect of Anogeissus leiocarpus Guill and Perr ethanolic leaf extract on blood glucose and other biochemical indices in alloxan-induced diabetic adult male Wistar albino rats. Diabetes mellitus was induced in overnight-fasted rats by a single intraperitoneal injection of alloxan monohydrate $(150 \mathrm{mg} / \mathrm{kg}$ body weight). Diabetic rats were then treated with the extract for 14 days. Blood glucose, lipid profile and liver glycogen levels were determined. After the treatment with the extract, the fasting blood glucose levels significantly reduced $(\mathrm{p}<0.05)$ in treated diabetic rats $(62.2 \pm 18.4$ $\mathrm{mg} / \mathrm{dl})$ compared to untreated diabetic rats $(73.8 \pm 8.2 \mathrm{mg} / \mathrm{dl})$. There was also significant $(\mathrm{p}<0.05)$ reduction in the hyperlipidemic parameters. The results revealed that A. leiocarpus ethanolic extract has antidiabetic and hypolipidemic effects in alloxan-induced diabetic rats.
\end{abstract}

Key words: Anogeissus leiocarpus, antidiabetic, diabetes, hyperglyceamia, hypolipidemia.

\section{INTRODUCTION}

Diabetes mellitus is a chronic progressive metabolic disorder characterized by dysfunction in protein, fat, carbohydrate and insulin metabolism which result in hyperglycaemia due to either an absolute deficiency of insulin secretion or reduction of its biological effectiveness or both. Moreover, diabetes increases the risks of micro vascular damage (retinopathy, nephropathy and neuropathy) as well as macro vascular complications (ischemic heart disease, stroke and peripheral vascular disease). ${ }^{1,2}$

Correspondence to: Philip F. Uzor

E-mail: Philip.uzor@unn.edu.ng; Tel: +234-803 7008294

Dhaka Univ. J. Pharm. Sci. 17(1): 65-72, 2018 (June)
People living with diabetes mellitus across the world are expected to rise to 592 million in 2035 and the pandemic is worst in developing countries like Nigeria, where the cost of treating or managing diabetes mellitus is relatively out of the reach of many diabetic patients. ${ }^{3}$

Researchers have found that over 200 pure phytochemicals are known to possess hypoglycaemic activity or insulin-potentiating action in vitro and in vivo. ${ }^{4-6}$ Diabetes management devoid of side effects still poses a big challenge to the medical professionals. Therefore, the need to develop natural herbal products/alternatives with insulin-like bioactivity, having little or no side effects is 
imperative. Folkloric cultures around the world including Africa, and in particular Nigeria, have successfully and safely utilized medicinal plants for the management of diabetes mellitus. ${ }^{7-9}$

Anogeissus leiocarpus (Guill and Perr) belongs to the phylum Tracheophyta, order Myrtales and family Combretaceae (Combretoideae). In Nigeria, it is referred to as marke (Hausa), kojoli (Fulani), annum (Kanuri), ayin or orin-odan ainy (Yoruba), atara (Igbo) and kukunchi (Nupe). It is an evergreen tree and distributed from tropical West to Central and East Africa through tropical South East Asia. It germinates in new soil produced by seasonal wetlands and grows at the edge of forest in the savannah and along riverbanks forming gulley forest. It is a very graceful tropical tree and occurs in the most of the savannah areas from the driest regions to the borders of the forest zone. The tree is grown commercially since 2000 for the production of cosmetics in the Koro region of Burkina Faso. ${ }^{8,9}$ The bark, leaves and roots of A. leiocarpus are used in traditional medicine for human and animals. A decoction of the leaves or leafy twigs is used against yellow fever, jaundice, hepatitis, common cold, headache and diabetes by local communities. They have also antimicrobial and anthelmintic activities and are usually taken as decoctions or aqueous extracts. ${ }^{9-12}$ However, not much detailed studies on the hypoglycaemic and associated dyslipidaemic and glycogenetic status of diabetic rats have been studied on this plant species. This study was, therefore, carried out to examine the effect of ethanolic leaf extract of A. leiocarcpa on the hyperglycaemic and the concomitant dyslipidaemic as well as glycogenetic status in an experimental animal model of diabetes.

\section{METHODS}

Plant materials and extraction. The leaves of A. leiocarpus Guill and Perr was collected from Adani in Uzo-Uwani in Enugu state, Nigeria. The sample was identified by a botanist - Mr. A.O. Ozioko of the Herbarium unit of the International Center for Ethnomedicine and Drug Development
(InterCEDD), Nsukka Nigeria. Voucher specimen was deposited in the Herbarium of the Department of Plant Science and Biotechnology, University of Nigeria, Nsukka, Nigeria. The fresh leaves of $A$. leiocarpus were washed in running tap water to remove dirt and other extraneous materials, drained and dried under shade for five (5) days. They were then pulverized into fine powder using sterile blender. The powdered sample was labeled and stored in a refrigerator $\left(4^{\circ} \mathrm{C}\right)$ until used. Five hundred gram $(500 \mathrm{~g})$ of the powdered leaves of A. leiocarpus was macerated in 1.5 litres of ethanol for 48 hours at room temperature. The mixture was filtered with Whatman No. 4 filter paper, then centrifuged and decanted to remove any remaining particles. The filtrate was concentrated to a semi-solid residue using a rotary vacuum evaporator.

Animals. Forty eight (48) healthy male adult albino Wistar rats aged 4 months and weighing between (170-180 gm mean weight: $175 \mathrm{mg}$ ) were used for the antidiabetic study while Swiss albino mice (21-25 g) of either sex were used for acute toxicity study. They were purchased from the animal house unit of the Department of Zoology and Environmental Biology, University of Nigeria, Nsukka. The animals were kept in standard polypropylene cages at room temperature and at 60$65 \%$ relative humidity with $12 \mathrm{hrs}$ day: $12 \mathrm{hrs}$ night cycle. They were fed with normal laboratory diet and allowed to drink water ad libitum. Animal experiments were approved by the ethics committee of the University of Nigeria Nigeria (NHREC/05/01/20088). The experiments were performed according to the guidelines set for the care and use of laboratory animals and with the rules formulated under the Animal Welfare Act by the United States Department of Agriculture (USDA).

Acute toxicity test. Ten (10) mice were randomly assigned into two groups $(\mathrm{n}=5)$ to determine the possible toxic effect of A. leiocarpus leaf extract. The extract was administered orally by gavage to the mice at a dose of $1 \mathrm{~g} / \mathrm{kg}$ and $5 \mathrm{~g} / \mathrm{kg}$ body weight, respectively. The mice were observed for $12 \mathrm{hrs}$ after the administration of the extract to 
check for toxic symptoms. They were then kept under a closed watch for two weeks.

Induction of diabetes. Diabetes mellitus was induced in overnight-fasted rats by a single intraperitoneal injection of alloxan monohydrate (Sigma, St Louis, MO; $150 \mathrm{mg} / \mathrm{kg}$ bodyweight) dissolved in $0.2 \mathrm{ml}$ of normal saline. Hyperglycemia was confirmed by the elevated blood glucose levels determined at 72 hours after injection. The animals with elevated blood glucose concentration of more than $200 \mathrm{mg} / \mathrm{dl}$ from their baseline average level of $74 \pm 6.4 \mathrm{mg} / \mathrm{dl}$ of normoglycaemic rats were confirmed diabetic and used for the study. Blood samples were collected from the tails of the rats for the determination of baseline (before induction of diabetes) and initial (after induction of diabetes) glucose concentrations using electronic glucometer with glucose test strips (Accucheck and Softclix ${ }^{(R)}$, Roche, Mannheim, Germany).

Experimental design. Forty eight (48) rats were randomly assigned into six groups of 8 replicate each $(n=8)$ according to their body weights as follows:

Group I - normal control (normoglycaemic)

Groups II - negative control (untreated diabetic rats)

Group III - positive control (glibenclamide treated;

$5 \mathrm{mg} / \mathrm{kg}$ body weight) (glibenclamide sourced from RBI Research Biochemical International, MA, USA)

Groups IV - treated with $200 \mathrm{mg} / \mathrm{kg}$ body weight of the extract

Group V - treated with $400 \mathrm{mg} / \mathrm{kg}$ body weight of the extract

Group VI - treated with $600 \mathrm{mg} / \mathrm{kg}$ body weight of the extract.

The route of administration of the extract was oral gavage with the aid of an oral intubation tube. The experiment lasted for 14 days; 3 days for induction, 10 days for treatment and the blood glucose was assayed on day 14. Subsequently, the animals were sacrificed and blood collected by cardiac puncture into a tube containing fluoride oxalate as anticoagulant. The blood was then used for lipid profile (triglycerides, cholesterol, high density lipoprotein, low density lipoprotein) and glycogen analysis. The body weights of the experimental animals were recorded prior to the treatment and sacrifice.

Biochemical analysis. Serum cholesterol, triglycerides, high density lipoprotein (HDL) and low density lipoprotein (LDL) were determined by standard methods as previously described. ${ }^{13}$

Total cholesterol. The serum was diluted with distilled water (1:19) while the cholesterol standard was diluted with glacial acetic acid (1:20); they were put in stoppered test tubes and shaken vigorously. The tubes were put in boiling water bath for 90 seconds, cooled in running tap water for 5 minutes and subsequently the absorbance was read out at $560 \mathrm{~nm}$ against the blank. ${ }^{13}$

High density lipoprotein. One mililiter $(1 \mathrm{ml})$ of serum was pipetted into a centrifuge tube, added $0.1 \mathrm{ml}$ of PTA (phosphotungstic acid) reagent and mixed properly. Then $0.05 \mathrm{ml}$ of magnesium chloride was added and mixed properly. It was centrifuged at $250 \mathrm{rpm}$ or $1500 \mathrm{~g}$ for 30 minutes. The clear supernatant was carefully removed with a Pasteur pipette, then the HDL-cholesterol level in the supernatant was estimated as follows: serum HDLcholesterol $(\mathrm{mg} / \mathrm{dl})=$ absorbance test $\times 115{ }^{13}$

Triglycerides. The tubes were mixed thoroughly in a vortex mixer for 30 seconds and allowed to stand at room temperature for 10 minutes for clear separation of the two layers; the top solvent layer was then used for further assay. Another set of three stoppered test tubes were prepared and mixed properly, incubated at $60^{\circ} \mathrm{C}$ for 10 minutes and cooled to room temperature. Then $0.1 \mathrm{ml}$ periodate reagent was added to each tube and mixed well. Further, $1.0 \mathrm{ml}$ of acetylacetone reagent was added to each tube and mixed properly, incubated at $60^{\circ} \mathrm{C}$ for 10 minutes and cooled to room temperature. The tubes were centrifuged and the upper phase liquid transferred to fresh tubes and the absorbance of sample and standard were read out at $420 \mathrm{~nm}$ against the blank. ${ }^{13}$ 
Low density lipoprotein. This was calculated as follows: LDL cholesterol $(\mathrm{mg} / \mathrm{dl})=$ Total cholesterol (HDL) cholesterol $+0.46 \times$ triglyceride $\mathrm{dl} / \mathrm{l})^{13}$.

Statistical analysis. Data obtained were analyzed using Statistical Product for Service Solution (SPSS, Armonk, NY: IBM Corp., version 21). Analysis of variance (ANOVA) and Duncan's New Multiple Range Test (DNMRT) were used to separate and compare means. Significant difference was accepted at $\mathrm{p}<0.05$.

\section{RESULTS AND DISCUSSION}

Results of acute toxicity shows that there was no observed acute toxicity even at the dose of 5000 $\mathrm{mg} / \mathrm{kg}$ body weight of the plant extract.

Table 1 shows the changes in fasting blood glucose before and after treatment in all the six groups of animals. The fasting blood glucose level of untreated diabetic rats was significantly $(\mathrm{p}<0.05)$ higher than those in the treated diabetic groups. We observed $25.4 \pm 1.2 \%$ and $23.2 \pm 2.3 \%$ decreases in fasting blood glucose in the glibenclamide treated and extract $(600 \mathrm{mg} / \mathrm{kg})$ treated rats respectively. The dose of $600 \mathrm{mg} / \mathrm{kg}$ appeared to perform slightly better than other treatment doses of the extract; however, the difference was not significant ( $\mathrm{p}>$ $0.05)$.

Figure 1 depicts the body weight changes and food intake in normal and diabetic rats administered with ethanolic leaf extract of A. leiocarpa and glibenclamide. Decreasing trend in the average food intake was observed among the diabetic groups. The diabetic groups ate less food compared to the normoglycaemic group. The untreated diabetic rats lost more weight than the treated rats. As a result of the treatment, there was an increase in the weight of the treated rats, however, the difference between the glibenclamide treated rats and that of the extract was not significant $(\mathrm{p}>0.05)$.

Table 1. Effect of treatment with A. leiocarpus extract for $\mathbf{1 0}$ days on blood glucose of normal and diabetic rats.

\begin{tabular}{llll}
\hline $\begin{array}{l}\text { Group of rats } \\
(\mathrm{n}=8)\end{array}$ & $\begin{array}{l}\text { Dose of extract }(\mathrm{mg} / \mathrm{kg} \\
\text { body weight })\end{array}$ & $\begin{array}{l}\text { Fasting blood glucose } \\
\text { before treatment }(\mathrm{mg} / \mathrm{dl})\end{array}$ & $\begin{array}{l}\text { Fasting blood glucose } \\
\text { after treatment }(\mathrm{mg} / \mathrm{dl})\end{array}$ \\
\hline I & Normal rats & $74.33 \pm 4.2$ & $68.32 \pm 2.2$ \\
II & Untreated diabetic rats & $222.20 \pm 12.6^{\#}$ & $232.42 \pm 10.4$ \\
III & GTDR & $355.5 \pm 18.6$ & $73.8 \pm 18.2^{*}$ \\
IV & $200 \mathrm{mg}$ & $309.8 \pm 20.12$ & $66.8 \pm 24.4^{*}$ \\
V & $400 \mathrm{mg}$ & $248.3 \pm 16.4$ & $70.2 \pm 20.6^{*}$ \\
VI & $600 \mathrm{mg}$ & $269.2 \pm 22.6$ & $66.2 \pm 18.4^{*}$ \\
\hline
\end{tabular}

Results are expressed as mean \pm S.D of 8 determinations, \# $\mathrm{p}=0.001$ compared to the blood glucose level in normal rats, ${ }^{*} \mathrm{p}=0.001$ compared to the initial blood glucose level in treated diabetic rats and also final blood glucose level in untreated diabetic rats

The serum cholesterol, triglyceride, HDL, LDL and hepatic glycogen levels in all the six groups of rats are shown in table 2. The cholesterol and triglyceride levels were significantly $(\mathrm{p}<0.05)$ higher in the untreated diabetic rats compared to those in both the glibenclamide and the extract treated diabetic animals. On the other hand, the HDL levels of the untreated diabetic rats were lower than both the glibenclamide and the extract treated rats. However, the HDL values of glibenclamide and the extract treated rats were comparable $(\mathrm{p}>0.05)$. The LDL values of the untreated diabetic rats were significantly $(\mathrm{p}<0.05)$ higher than in glibenclamide and extract treated rats (Table 2). The treatment with A leiocarpus ethanolic leaf extract resulted in lowering of both the cholesterol and the triglyceride levels in the extract treated diabetic animals which compared favourably with that of glibenclamide and the normoglycaemic rats. The hepatic (liver) glycogen levels of the untreated diabetic rats were 
significantly $(\mathrm{p}<0.05)$ lower than those in glibenclamide, the normoglycaemic and extract treated rats. The results showed that treatment with $A$. leiocarpus leaf extract markedly enhanced the liver glycogen levels significantly $(\mathrm{p}<0.05)$ as observed in the higher levels of hepatic glycogen of the treated diabetic groups compared to the untreated diabetic rats.

Results of toxicity study indicated that the extract was safe even at high dose of $5000 \mathrm{mg} / \mathrm{kg}$ b.w.. A previous study has also shown the safety of the plant extract with $\mathrm{LD}_{50}$ of $1400 \mathrm{mg} / \mathrm{kg}$ (i.p.). ${ }^{14}$

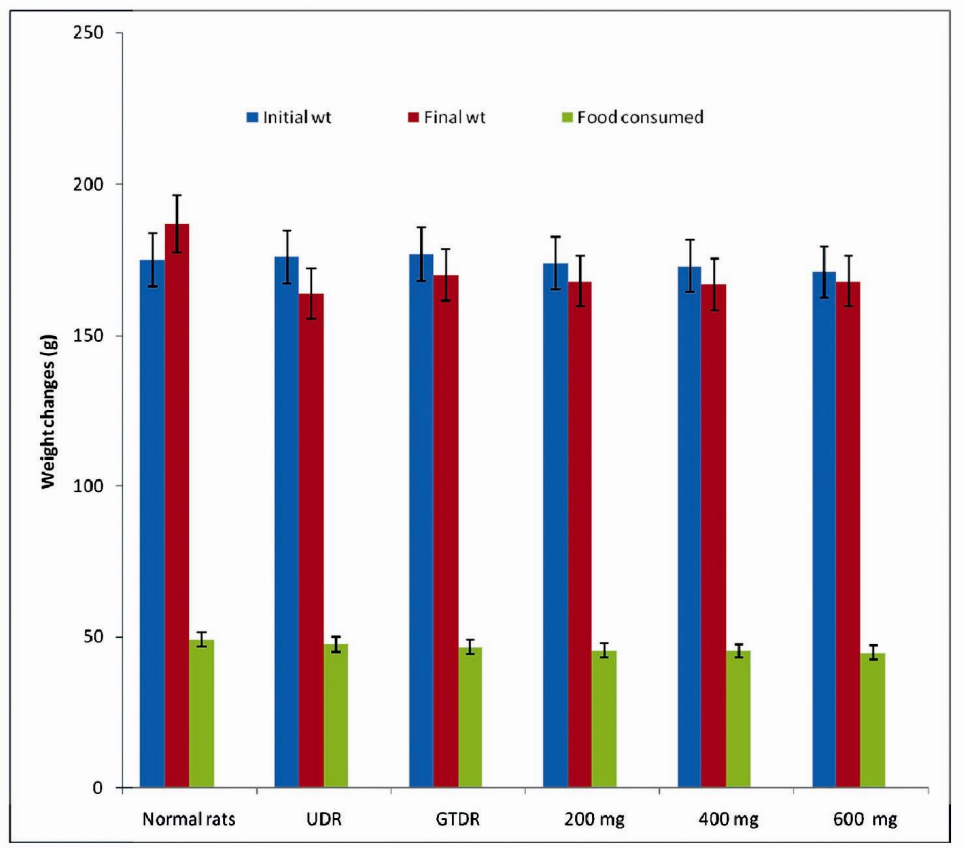

Figure 1. Effect of A. leiocarpus extract on the weight of the rats.

$\mathrm{UDR}=$ Untreated, GTDR = glibenclamide treated diabetic rats, $200 \mathrm{mg}-600 \mathrm{mg}$ (extract treated diabetic rats).

Table 2. Effect of A. leiocarpus leaf extract on serum cholesterol, triglyceride, high density lipoprotein (HDL), low density lipoprotein (LDL) and hepatic glycogen level.

\begin{tabular}{lllllll}
\hline $\begin{array}{l}\text { Group } \\
\text { of rats } \\
(\mathrm{n}=8)\end{array}$ & $\begin{array}{l}\text { Dose of extract } \\
(\mathrm{mg} / \mathrm{kg} \text { body weight })\end{array}$ & $\begin{array}{l}\text { Cholesterol } \\
(\mathrm{mg} / \mathrm{dl})\end{array}$ & $\begin{array}{l}\text { Triglyceride } \\
(\mathrm{mg} / \mathrm{dl})\end{array}$ & $\begin{array}{l}\mathrm{HDL} \\
(\mathrm{mg} / \mathrm{dl})\end{array}$ & $\begin{array}{l}\mathrm{LDL} \\
(\mathrm{mg} / \mathrm{dl})\end{array}$ & $\begin{array}{l}\text { Hepatic glycogen } \\
(\mathrm{mg} \text { glucose } \\
\text { equivalent per } \\
\text { gram wet tissue })\end{array}$ \\
\hline I & Normal rats & $42.67 \pm 7.6$ & $30.88 \pm 0.66$ & $35.22 \pm 0.34$ & $6.41 \pm 0.24$ & $14.24 \pm 0.52$ \\
II & Untreated diabetic rats & $78.28 \pm 3.4^{\#}$ & $125.14 \pm 8.24^{\#}$ & $28.20 \pm 0.52^{\#}$ & $12.22 \pm 0.42^{\#}$ & $7.86 \pm 1.52^{\#}$ \\
III & GTDR & $63.62 \pm 2.8^{*}$ & $24.62 \pm 0.62^{*}$ & $46.75 \pm 0.33^{*}$ & $8.89 \pm 0.22^{*}$ & $13.42 \pm 0.66^{*}$ \\
IV & 200mg & $49.17 \pm 1.6^{*}$ & $40.62 \pm 0.44^{*}$ & $35.29 \pm 0.26^{*}$ & $5.75 \pm 0.34^{*}$ & $12.94 \pm 0.62^{*}$ \\
V & $400 \mathrm{mg}$ & $41.54 \pm 1.8^{*}$ & $40.65 \pm 0.52^{*}$ & $33.95 \pm 0.46^{*}$ & $6.11 \pm 0.46^{*}$ & $13.42 \pm 0.56^{*}$ \\
VI & $600 \mathrm{mg}$ & $56.21 \pm 1.4^{*}$ & $50.37 \pm 0.46^{*}$ & $45.67 \pm 0.22^{*}$ & $9.21 \pm 0.32^{*}$ & $13.62 \pm 0.58^{*}$ \\
\hline
\end{tabular}

Results are expressed as Mean \pm S.D of 3 determinations, HDL - High Density lipoprotein, LDL- Low Density Lipoprotein, GTDR= glibenclamide-treated diabetic rats, \# $\mathrm{p}=0.001$ compared to normal rats, ${ }^{*} \mathrm{p}=0.001$ compared to untreated diabetic rats.

Administration of A. leocarpus leaf extract resulted in significant $(\mathrm{p}<0.05)$ lowering of blood glucose, lipid profile and robust elevated hepatic glycogen in alloxan-induced diabetic rats. A10-day treatment regimen with 200,400 and $600 \mathrm{mg} / \mathrm{kg}$ body weight of the extract caused significant $(\mathrm{p}<0.05)$ 
decreases of the elevated fasting blood glucose levels of the treated diabetic rats compared to the untreated diabetic rats. There were significant $(\mathrm{p}<0.05)$ weight losses in the diabetic animals and the subsequent treatment with A. leiocarpus leaf extract resulted in the improvement of their body weights, compared to the untreated diabetic rats. These results are in line with the report of other workers that A. leiocarpus leaves contain high bioactive substances, notably antioxidants such as ellagic, gallic and gentisic acids, derivatives of gallic and ellagic acids and several flavonoids (derivatives of quercetin and kaempferol which are reported to have hypoglycaemic action. ${ }^{5,10,11}$ It has also been shown that plant nutrients play protective roles against oxidative stress in diabetic rats. ${ }^{15,16}$ The ability of the A. leiocarpus ethanolic leaf extract to protect the rats against oxidative stress could be attributed to its hypoglycaemic principles. ${ }^{17-20}$ The mechanism of action that brings about the hypoglycaemic effect may be by increasing either the pancreatic secretion of insulin from $\beta$-cells of the islet of Langerhans or its release from pro-insulin form. ${ }^{21}$ It has been shown that alloxan administration results in the destruction of $\beta$-cells of the pancreas, thereby precipitating hyperglycaemia or diabetes, perhaps due to selectively inhibiting glucose-induced insulin secretion, by blocking the activity of the $\beta$-cells glucose sensor, glucokinase. ${ }^{14,22,23}$ It seems most probable that the extract produced the required hypoglycaemic effect in diabetic rats by a mechanism other than the stimulation of insulin release from $\beta$ cell. ${ }^{4}$ It has been reported that certain flavonoids have the capability of $\beta$-cells regeneration of pancreas ${ }^{15,24}$ and sterols have been reported to reduce blood glucose in experimental animals. It is perhaps the synergistic effect of the robust phytochemicals and micronutrients present in this plant (the result not shown here) that result in its hypoglycemic effect. For example, trivalent chromium has been shown to enhance the ability of insulin to remove fat from the blood. ${ }^{5-27}$ The treatment with the extract resulted in improved rate of glycogenesis as depicted by higher levels of hepatic glycogen in the treated diabetic animals compared to untreated rats (Table 2). Other authors also reported similar observation in diabetic animals treated with plant products. ${ }^{7,28}$

In the present study, there was significant ( $\mathrm{p}<$ 0.05) reduction in the total cholesterol and triglyceride levels of the treated diabetic rats compared to the untreated rats. Some authors have observed increased risk of coronary artery disease in subjects with diabetes mellitus due to lipoprotein abnormalities associated with diabetes mellitus. ${ }^{1}$ Hypertriglycerides and low levels of high density lipoprotein (HDL) are the most common lipid abnormalities in diabetic patients. ${ }^{19}$ The non-insulin dependent diabetic (NIDDM) patient with mild fasting hyperglycaemia commonly has mild triglyceridaemia due to overproduction of triglyceride-rich lipoprotein in the liver associated with decreased high density lipoprotein cholesterol level. ${ }^{22}$ It has also been shown that the most typical lipoprotein pattern in diabetes, known as diabetic dyslipidaemia or atherogenic dyslipidaemia, consists of moderate elevation in triglyceride (TAG) levels, low HDL cholesterol values and elevated low density lipoprotein (LDL) cholesterol. $^{23}$ Observed accumulation of lipid may be dependent on a variety of alterations in metabolic and regulatory mechanisms, which may be due to insulin deficiency or due to insulin resistance. ${ }^{24,28}$

\section{CONCLUSION}

The results from the present study revealed that ethanolic leaf extract of A. leiocarpus is safe for use and has beneficial effects on fasting blood glucose level along with improving hyperlipidaemia associated with diabetes mellitus. Future studies should focus on pharmacological and biochemical investigations to explain possible mechanism of the antidiabetic action and hypolipidemic effect of the plant. Furthermore, the active constituents responsible for the antidiabetic activities should be isolated and characterized.

Competing interests: The authors declare that they have no competing interests. 
Funding: No external or internal funding was obtained for this study.

\section{Authors' contributions}

OUS designed and also supervised the work, UCC performed the experiments, NEI and PFU contributed ideas and helped in preparing the manuscript. OEO provided the plant material and contributed ideas. NP, EN, IN, EJE participated in the supervision of the study. All authors read and approved the manuscript.

\section{ACKNOWLEDGEMENTS}

We are thankful to University of Nigeria Nsukka for providing the facilities for the study.

\section{REFERENCES}

1. Mandavia, C.H., Aroor, A.R., deMarco, V. and Sowers, J.R. 2013. Molecular and metabolic mechanisms of cardiac dysfunction in diabetes. Life Science 92, 601-608.

2. World Health Organization. Diabetes [cited 2016 November 01].Available www.who.int/topics/diabetes_mellitus/en/.

3. WHO."Diabetes fact Sheet, No. 312" 2013 [cited 2016 June 01]. Available www.who.int/mediacentre/facsheet/fs.312en/

4. Raman, M.S., Akter, R., Mazumdar, S., Islam, F., Mouri, N.J., Nandi, N.C. and Mahmud, A.S.M. 2015. Antidiabetic and antidiarrhoeal potentials of ethanolic extracts of aerial parts of Cynodon dactylon Pers. Asian Pac J. Trop. Biomed. 5, 658-662. Doi:10.1016/j.apjtb.2015.04.011

5. Osadebe, P.O., Uzor, P.F., Omeje, E.O., Agbo, M.O. and Obonga, W.O. 2014. Hypoglycemic activity of the extract and fractions of Anthocleista vogelii (Planch) stem bark. Trop J. Pharm. Res. 13, 1437-1443.

6. American Diabetes Association. 2010. Diagnosis and classification diabetes mellitus. Diabetes Care 33, 62-69.

7. Keter, L.K. and Mutiso, P.C. 2012. Ethnobotanical studies of medicinal plants used by traditional health practitioners in the management of diabetes in the lower Eastern Province, Kenya. J. Ethnopharmacol. 139, 74-80.

8. Rizvi, S.I. and Mishra, N. 2013. Traditional Indian medicine used for the management of diabetes mellitus. J. Diab Res. Volume 2013, Article ID 712092, 11 pages.

9. Ezulike, U.F. and Prieto, J.M. 2014. The use of plants in the traditional management of diabetes in Nigeria: pharmacological and toxicological consideration. $J$. Ethnopharmacol 155, 857-924.
10. Ahmad, H. and Arbab, H. 2014. Review on Anogeissus leiocarpa: A potent African traditional drug. Intl. J. Res. Pharm. Chem. 4, 496-500.

11. Belemnaba, L., Ouédraogo, S., Auger, C., Chataigneau, T., Traore, A., Guissou, I.P., Lugnier, C., Schini-Kerth, V.B. and Bucher, B. 2013. Endothelium-independent and endotheliumdependent vasorelaxation by a dichloromethane fraction from Anogeissus leiocarpus (DC) Guill. Et Perr. (Combretaceae): Possible involvement of cyclic nucleotide phosphodiesterase inhibition. Afr. J. Trad. Compl. Altern. Med. 10, 173-179.

12. Chidozie, V.N. and Adoga, G.I. 2014. Toxicological effects of aqueous extracts of Anogeissus leiocarpus leaves, Carica papaya leaves and Magnifera indica stem bark (A herbal product used against typhoid fever) on albino rats. Cancer Biol. 14, 26-34.

13. AOAC. Official methods of analysis ( $16^{\text {th }}$ edition). Association of Official Analytical Chemists, 2010; Washington, D.C.

14. Agaie, B.M., Onyeyili, P.A., Muhammad, B.Y. and Ladan, M.J. 2007. Acute toxicity effects of the aqueous leaf extract of Anogeissus leiocarpus in rats. Afr. J. Biotech. 6, 886-889.

15. Sellamuthu, P.S., Arulselvan, P., Muniappani, B.P., Fakurazi, S. and Kandasamy, M. 2013. Mangiferin from Salacia chinensis prevents oxidative stress and protects pancreatic $\beta$ cells in streptozotocin-induced diabetic rats. J. Med. Food 16, 719-727.

16. Madkor, H.R., Mansour, S.W. and Ramadan, G. 2011. Modulatory effects of garlic, ginger, turmeric and their mixture on hyperglycaemia, dyslipidemia and oxidative stress in stretozotocin-nicotinamide diabetic rats. Br. J. Nutr. 105, 1210-1217.

17. Parimalu, M. and Shoba, F.G. 2013. Phytochemical analysis and in vitro antioxidant activity of hydroalcoholic seed extract of Nymphaea nouchali Burm.f. Asian Pac. J. Trop. Biomed. 3, 887-895.

18. Matough, F.A., Budin , S.B., Zariyantey, A, Alwahhaibi, H.N. and Mohamed, J. 2012. The role of oxidative stress and antioxidants in diabetic complications. Sultan Qaboos Univ. Med. J. 12, 5-18.

19. Rotimi, S.O., Ademuyiwa, O.A. and Adamson, I. 2013. Improvement of diabetic dyslipidemia by legumes in experimental rats. Afr. J. Food Agric. Nutr. Dev. 13, 76067623.

20. Aquacheri, Q., Saka, S., Krim, M., Messaadia, A. and Maidi, I. 2015. Oxidative stress-related parameters in type 2 diabetes mellitus. Canadian J. Diab. 39, 44-49.

21. Chaturvedi, P. 2012. Antidiabetic potentials of Momordica charantia: multiple mechanisms behind the effects. J. Med. Food 15, 101-107. 
22. Singh, P.K., Baxi, D., Benrgee, S. and Ramachandran V. 2012. Therapy with methanolic extract of Pterocarpus marsupum Rcxb and Ocimum sanctum Linn reverses dyslipidemia and oxidative stress in alloxan-induced type 1 diabetic rat model. Expt. Toxicol. Pathol. 64, 441-448.

23. Aja, P.M., Ibiam, U.A., Nwali, B.U., Orji, O.U., Edwin, N. and Afiukwa, C.A. 2015. Evaluation of effects of ethanol extracts of Moringa oleifera and Cajanus cajan leaves on lipid profiles, in alloxan- induced diabetic albino rats. Global J. Biotechnol. Biochem. 10, 71-76.

24. Martin, M.A., Ramos, S., Cordero-Herrero, I., Bravo, L. and Goya, L. 2013. Cocoa phenolic extract protects pancreatic beta cells against oxidative stress. Nutrient 5, 2955-2968.
25. Micheal, V. 2011. The malnutrition of obesity: Micronutrient deficiencies that promote diabetes. J. Clin. Endocrinol. Metabol. 92, 2011-2029.

26. Joseph, E., Disivestro, R. and de Blanco, E.J.C. 2015. Triglyceride lowering by chromium picolinate in type 2 diabetic people. Intl. J. Nutr. Metab. 7, 24-28.

27. Anjum, C., Henry, J. and Kaur, B. 2012. Micronutrients status in type 2 diabetes. A review: Adv. Food Nutr. Res. 71, 55-100.

28. Owolabi, O.J., Inninh, S.O., Anaka, O.N. and Iyamu, O.A. 2014. Antidiabetic and hypolidemic effects of methanol leaf extract of Napoleona vogelii (Lecythidaceae) Hook \& Planch on alloxan-induced diabetes mellitus in rats. Trop J. Pharm. Res. 13, 1903-1909. 